\title{
Usefulness of cardiac hormones for evaluating valvular disease in cynomolgus monkeys (Macaca fascicularis)
}

\author{
Chungyu PAI ${ }^{1,2)}$, Shunya NAKAYAMA ${ }^{1,2)}$, Yasuyo ITO-FUJISHIRO ${ }^{1,2}$, \\ Kiichi KANAYAMA ${ }^{1)}$, Yoshiko MUNESUE ${ }^{3)}$, Tadashi SANKAI'), \\ Yasuhiro YASUTOMI ${ }^{2,4)}$, Hiroshi KOIE ${ }^{1) *}$ and Naohide AGEYAMA ${ }^{2) *}$ \\ 1)Laboratory of Veterinary Physiology/Pathophysiology, College of Bioresource Science, Nihon University, \\ Kanagawa 252-0880, Japan \\ ${ }^{2)}$ Tsukuba Primate Research Center, National Institutes of Biomedical Innovation, Health and Nutrition, Ibaraki \\ 305-0843, Japan \\ 3)The Corporation for Production and Research of Laboratory Primates, Ibaraki 305-0843, Japan \\ ${ }^{4)}$ Department of Molecular and Experimental Medicine, Mie University Graduate School of Medicine, Mie \\ 514-8507, Japan
}

J. Vet. Med. Sci.

83(4): 716-723, 2021

doi: 10.1292/jvms.20-0606

Received: 13 October 2020

Accepted: 11 February 2021

Advanced Epub:

9 March 2021

\begin{abstract}
Nonhuman primates are commonly used as experimental animals due to their biological resemblance to humans. In patients with cardiac disease, the levels of atrial natriuretic peptide (ANP) and brain natriuretic peptide (BNP) tend to increase in response to cardiac damage, and they are thus used as indicators for the diagnosis of human heart failure. However, no reference values for ANP and BNP have been reported for heart disease in nonhuman primates. In this study, we recorded the age, sex, and body weight of 202 cynomolgus monkeys, and performed evaluations to assess the ANP and BNP levels, electrocardiography and echocardiography, and accordingly divided the monkeys into two groups: healthy monkeys and those with spontaneous cardiac disease. Statistical analysis was performed to determine the relationship of ANP and BNP with the factors of age, sex, and body weight. No significant relationship was found between the levels of ANP and BNP and the factors of age, sex, and body weight. However, both the ANP and BNP levels were significantly different between the healthy monkeys and monkeys with valvular disease. Similar to humans, the ANP and BNP levels tended to increase with the progression of cardiac disease in monkeys. Based on these results, we concluded that ANP and BNP are indicators of cardiac disease in nonhuman primates, and that this nonhuman primate cardiac disease model is applicable for cardiology research in humans. KEY WORDS: atrial natriuretic peptide (ANP), brain natriuretic peptide (BNP), cynomolgus monkeys, nonhuman primate, valvular disease
\end{abstract}

Cardiovascular diseases are the leading cause of human morbidity and mortality. In cardiovascular disease research, laboratory animal models that closely simulate human diseases and can be easily bred are necessary. Cynomolgus monkeys (Macaca fascicularis) are noteworthy as experimental animal models, because their anatomies and physiological functions closely resemble those of humans. However, there have been few studies on cardiovascular diseases in macaque monkeys. In both humans and animals, such as canines and felines, the levels of atrial natriuretic peptide (ANP) and brain natriuretic peptide (BNP) increase when heart disease occurs due to heart damage and myocardial extension [22, 27]. ANP is secreted by atrial myocytes, and it promotes diuresis, decreases the volume of circulating blood, and is involved in suppressing the secretion of renin-aldosterone [22]. BNP has similar functions as ANP, but it is secreted by ventricular cardiac myocytes [27]. Therefore, the levels of ANP and BNP are used in the diagnosis of human heart failure [10,34]. However, little is known about the relationship between heart disease and the values of ANP and BNP in macaque monkeys.

The average life span of a macaque monkey is about 15 years in the wild, and about 30 years in rearing cages [3, 33]. Due to the extended lifespan of monkeys, chronic diseases that are found in humans can also be found in monkeys, including heart disease. Therefore, it is important to record and analyze valvular disease (VD) clinical conditions and special markers for cardiac disease. In this report, we investigated 202 macaque monkeys and compared the ANP and BNP levels between healthy monkeys and monkeys with cardiac disease, because there is little information on the relationship between heart disease and the ANP and BNP values in 
nonhuman primates. The results of this study are expected to be useful for facilitating the diagnosis of early stage cardiac disease and for improving the veterinary care of nonhuman primates. However, there are currently no established reference ranges for the cardiac hormones ANP and BNP in healthy monkeys; thus, this study attempted to determine the normal ranges of ANP and BNP in monkeys. We believe that the data gained from this study will be useful for improving the quality of life of not only cynomolgus monkeys, but all kinds of nonhuman primates that are used as laboratory animals.

\section{MATERIALS AND METHODS}

\section{Animals}

We included 202 cynomolgus monkeys (male: 72, female: 130), which were bred at the Tsukuba Primate Research Center (Tsukuba, Japan). Since cynomolgus monkeys reach sexual maturity at about 4 years of age, this investigation examined only monkeys over the age of 5 years. All monkeys were housed in stainless steel cages at $23^{\circ} \mathrm{C}$ to $28^{\circ} \mathrm{C}$ with $50 \%$ to $70 \%$ humidity, 12 air changes/hr, and a $12 / 12-\mathrm{hr}$ light/dark cycle, and they were fed $70 \mathrm{~g}$ of commercial monkey chow (CMK-2; CLEA Japan, Inc., Tokyo, Japan) and $200 \mathrm{~g}$ of fruit daily. The characteristics of the monkeys were as follows: in healthy male monkeys, the mean age was $9.29 \pm 5.71$ years, and the mean weight was $5.10 \pm 1.14 \mathrm{~kg}$; in healthy female monkeys, the mean age was $15.7 \pm 6.57$ years, and the mean weight was $4.01 \pm 1.04 \mathrm{~kg}$; in male VD monkeys, the mean age was $12.27 \pm 8.56$ years, and the mean weight was $5.43 \pm 1.25 \mathrm{~kg}$; and in female VD monkeys, the mean of age was $17.90 \pm 5.90$ years, and the mean weight was $4.02 \pm 1.00 \mathrm{~kg}$ (Table 1). Table 2 shows the detailed physical characteristics of the VD monkeys, including the mean weights and ages. These monkeys were temporary individual housing at this experimental period. There were several reasons why the monkeys were housed individually: first, to prevent the spread of infections, especially because many monkey pathogens are known to cause serious zoonoses, e.g., Macacine alphaherpesvirus 1, tuberculosis, simian AIDS virus, simian T cell leukemia virus, simian retrovirus, simian varicella virus, Shigella, and salmonella; second, to prevent injuries and reduce stress, since group breeding leads to ranking and a dominance hierarchy among the animals, which can stress the animals and increase fighting and injuries; third, to prevent unwanted pregnancies since monkeys bred in Tsukuba Primate Research Center are strictly controlled to ensure that the genealogy of the monkeys can be traced. From these perspectives, monkeys included in this colony have been housed individually for over 40 years $[11,33]$.

This study was conducted according to the Rules for Animal Care and Management of the Tsukuba Primate Center, the Guiding Principles for Animal Experiments Using Nonhuman Primates formulated by the Primate Society of Japan, and the Institute for Laboratory Animal Research (ILAR) Guide for Care and Use of Laboratory Animals [11, 12, 14]. The Animal Welfare and Animal Care Committee of the National Institutes of Biomedical Innovation, Health and Nutrition (NIBIOHN, Osaka, Japan) approved the experimental protocol.

\section{Physical characteristics of the monkeys}

In all of the examinations, the monkeys were immobilized by ketamine sedation (5-10 mg/kg intramuscularly; Ketalar, Daiichi Sankyo Propharma, Tokyo, Japan). After immobilization, we recorded the age, sex and body weight, and performed a simple physical examination. After auscultation, standard sixlead electrocardiograms were recorded using a three-channel electrocardiograph (D300, Fukuda ME, Tokyo, Japan). Then, the monkeys were placed in the right and left lateral recumbent positions using a cut-out table, and echocardiographic images were acquired from below using ProSound $\alpha 7$ ultrasonography systems (Hitachi Healthcare Manufacturing Co., Ltd., Kashiwa, Japan). Based on the results of transthoracic echocardiography, we categorized the monkeys with regurgitation at the mitral or tricuspid valve level into the VD group (VD monkeys), while monkeys without regurgitation, cardiac dilatation, or a fractional shortening decrease, such as cardiac abnormalities, were classified into the healthy group (Table 1). The distribution of VD is shown as a graph (Fig. 1). In human medicine, the

Table 1. Physical characteristics of the cynomolgus monkeys

\begin{tabular}{llrrr}
\hline & \multirow{2}{*}{ Sex } & $\mathrm{n}$ & \multicolumn{1}{c}{ Age } & Weight \\
\cline { 3 - 5 } & & & Mean $\pm \mathrm{SD}$ & Mean $\pm \mathrm{SD}$ \\
\hline Healthy & Male & 50 & $9.29 \pm 5.71$ & $5.10 \pm 1.14$ \\
& Female & 95 & $15.70 \pm 6.57$ & $4.01 \pm 1.04$ \\
VD & Male & 22 & $12.27 \pm 8.56$ & $5.43 \pm 1.25$ \\
& Female & 35 & $17.90 \pm 5.90$ & $4.02 \pm 1.00$ \\
\hline
\end{tabular}

$\mathrm{VD}$, valvular disease.

Table 2. Physical characteristics of the valvular disease (VD) monkeys

\begin{tabular}{llccc}
\hline \multirow{2}{*}{ Sex } & \multirow{n}{*}{$\mathrm{n}$} & \multicolumn{2}{c}{ Age } & Weight \\
\cline { 4 - 5 } & & & Mean \pm SD & Mean \pm SD \\
\hline MR & Male & 10 & $13.33 \pm 7.64$ & $5.35 \pm 1.09$ \\
& Female & 23 & $17.95 \pm 4.97$ & $3.78 \pm 0.89$ \\
TR & Male & 7 & $11.90 \pm 9.61$ & $5.82 \pm 1.43$ \\
\multirow{2}{*}{ MR\&TR } & Female & 9 & $15.70 \pm 7.20$ & $4.35 \pm 1.15$ \\
& Male & 5 & $13.96 \pm 10.18$ & $4.70 \pm 1.08$ \\
& Female & 3 & $21.89 \pm 3.80$ & $4.75 \pm 0.75$ \\
\hline
\end{tabular}

$\mathrm{MR}$, mitral regurgitation; TR, tricuspid regurgitation.

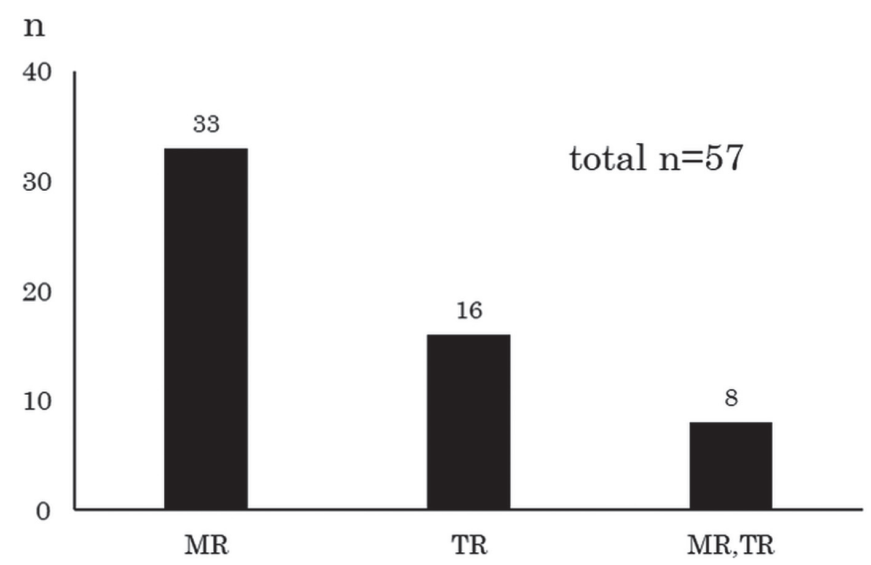

Fig. 1. Distribution of valvular disease (VD) cases. The graph shows the number of monkeys that were categorized into the VD group. 
classification of mitral regurgitation (MR) is based on the Carpentier Classification, which divides MR into three types based on leaflet motion [29, 35]. For assessing the severity, echocardiography is used to examine items, such as the proximal flow convergence, jet area or jet area/left atrial area ratio, and mitral inflow velocity [15, 29, 35]. In human MR, cardiac murmurs are known as holosystolic murmurs, and in serious cases, Carey Coombs murmurs have been found [35]. For tricuspid regurgitation (TR), the subjective symptoms are unclear, but holosystolic murmurs can be detected. Severity grading is done using echocardiography images to assess the flow convergence zone, the color flow jet area, and the proximal isovelocity surface area radius [35]. Although there is still no established VD classification for nonhuman primates, MR and TR were diagnosed by cardiac murmurs, electrocardiography, and echocardiography (Fig. 2) [35]. Electrocardiography was used to diagnose cardiac deviation and arrhythmia, and was performed using a 3-channel electrocardiograph (D300; Fukuda ME). The leads were set at commonly used positions, i.e., the right armpit, left armpit, right groin (ground), and left groin. It was difficult to observe clinical signs in the monkeys since they were bred in cages and unable to exercise vigorously. As such, the classification of symptoms was difficult in this study.

\section{ANP and BNP level analysis}

Blood samples for the measurements of ANP and BNP levels were collected from the femoral artery or femoral vein; the ANP and BNP values are the same in these two vessels [23]. To measure the ANP and BNP values, we used human kits for ANP (E test TOSOH II ANP, TOSOH Corp., Tokyo, Japan) and BNP (E test TOSOH II BNP, TOSOH Corp.). Measurements were performed by the automatic enzyme immunoassay devices AIA-360 and AIA-900 (TOSOH Corp.).

\section{Histopathology}

The hearts from two female monkeys that diagnosed with VD were cut into sagittal slices and fixed in $10 \%$ phosphate-buffered formalin. Gross sections were cut exactly perpendicular to the septum, and subsequently embedded in paraffin. Tissue sections (5 $\mu \mathrm{m}$ in thickness) were stained by hematoxylin and eosin (HE) staining or Masson's trichrome (MT) staining. Stained sections were imaged using a BX51 microscope equipped with a DP71 CCD camera (Olympus, Tokyo, Japan).

\section{Statistical analysis}

All data were analyzed by IBM SPSS Statistics software (IBM, Armonk, NY, USA). We used the chi-squared test to analyze the relationship between sex and the levels of ANP and BNP. The relationships with continuous variables, such as age and body weight, were analyzed by Student's $t$-test. Values of $P<0.05$ were considered to be indicative of statistically significant relationships in tables and graphs.

\section{RESULTS}

\section{ANP and BNP levels in healthy and VD monkeys}

In healthy monkeys, the mean ANP level was $25.63 \pm 18.62 \mathrm{pg} / \mathrm{ml}$, and the mean BNP level was $4.69 \pm 10.00 \mathrm{pg} / \mathrm{ml}$. In contrast, in VD monkeys, the mean ANP level was $45.03 \pm 59.40 \mathrm{pg} / \mathrm{ml}$, and the mean BNP level was $15.06 \pm 35.99 \mathrm{pg} / \mathrm{ml}$. We found that both the ANP and BNP levels differed significantly between the healthy and VD monkeys (ANP levels, $P=0.006$; BNP levels, $P=0.0018$; Fig. 3).

\section{Relationship between the ANP and BNP levels, age, body weight, and sex}

There was no correlation between age and cardiac hormone levels in both the healthy and VD monkeys $(P>0.05$, data not shown; Fig. 4). Regarding the association with body weight, there was no correlation between body weight and cardiac hormone levels ( $P>0.05$, data not shown). However, VD monkeys that were overweight tended to have a higher ANP level (Fig. 5).

There was no significant difference between females and males in both the healthy and VD monkey groups $(P>0.05$, data not shown).

Thus, there was no correlation between the parameters of age and body weight with the levels of ANP and BNP in both the healthy and VD monkey groups; in addition, there was no significant difference between the sexes.

\section{Echocardiography and histopathological examination of VD monkeys}

We diagnosed severe MR and TR in VD monkeys based on echocardiographic examinations (Fig. 5). Due to the tiny physique of cynomolgus monkeys, it was difficult to determine the cardiac function evaluation such as LA/AO, E peak, and A peak in this study. Echocardiography was only used to estimate regurgitation in this study. After the diagnoses were made, the monkeys were euthanized by sodium pentobarbital overdose due to their poor prognosis. Subsequently, we performed histopathological analyses for the VD monkeys that were diagnosed with severe MR or TR. Sections were stained by HE and MT staining. In cases with severe heart valve disease, ventricular enlargement and fibrosis of heart tissues were observed on histopathological examination (Fig. 6).

\section{DISCUSSION}

The results of this study are expected to be useful for the diagnosis of early stage cardiac disease and for improving the veterinary management of nonhuman primates, which are important as laboratory animals. When VD occurs, the heart has to 


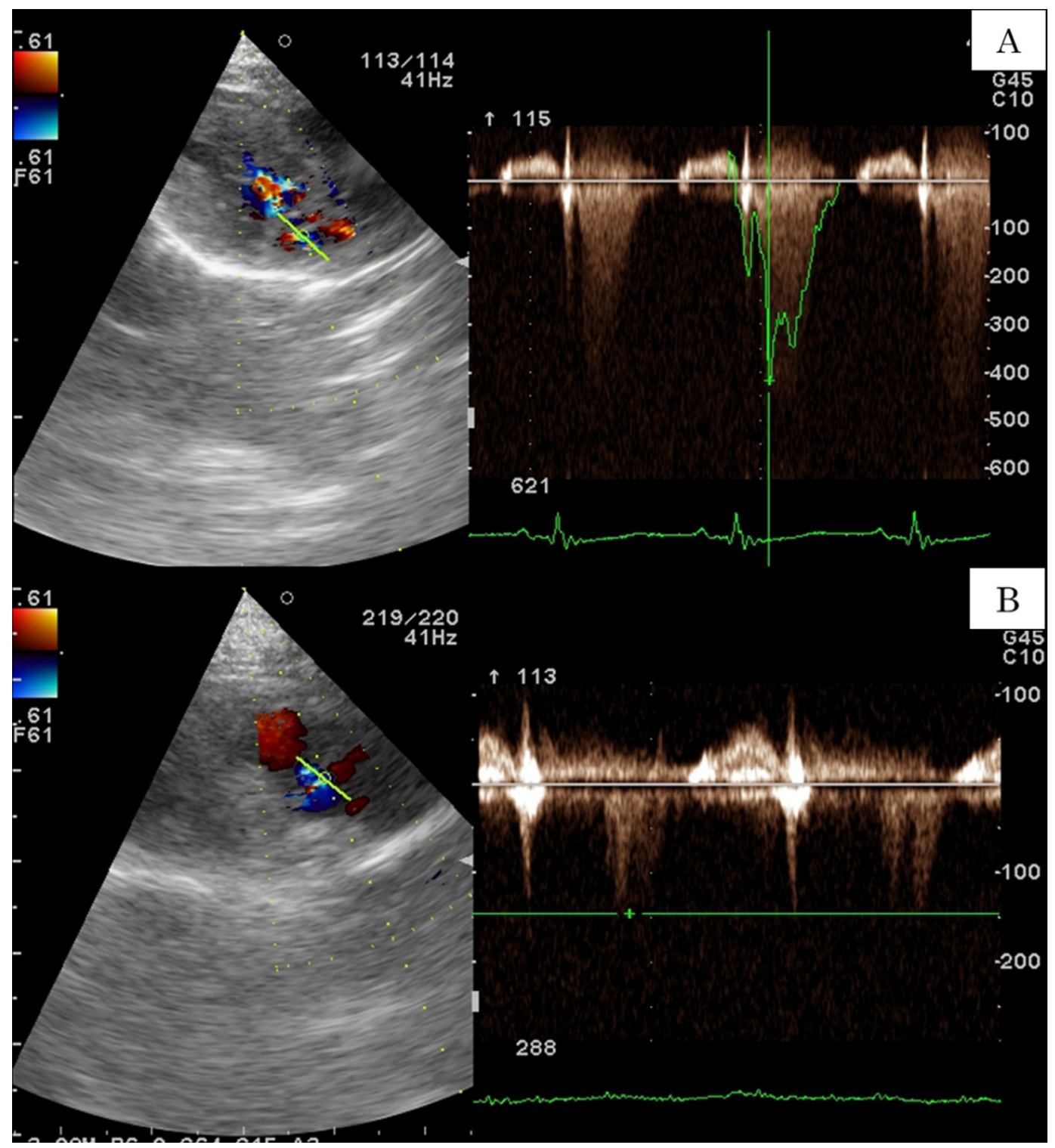

Fig. 2. Echocardiograms of monkeys with mitral regurgitation (MR) and tricuspid regurgitation (TR). Severe MR in a female VD monkey. This animal was diagnosed with MR due to rapid turbulence (peak velocity: $416.9 \mathrm{~cm} / \mathrm{sec}$; pressure gradient: $69.5 \mathrm{~mm} \mathrm{Hg}$ ) from the mitral valve (A). Severe TR in a female VD monkey. This animal was diagnosed with TR due to rapid turbulence (peak velocity: $145.7 \mathrm{~cm} / \mathrm{sec}$; pressure gradient: $8.5 \mathrm{~mm} \mathrm{Hg}$ ) from the tricuspid valve (B). The samples used for the histopathological examination in Fig. 6 were from the same individuals shown in the echocardiograms. Both of these monkeys were among the 202 cynomolgus monkeys examined in this study.

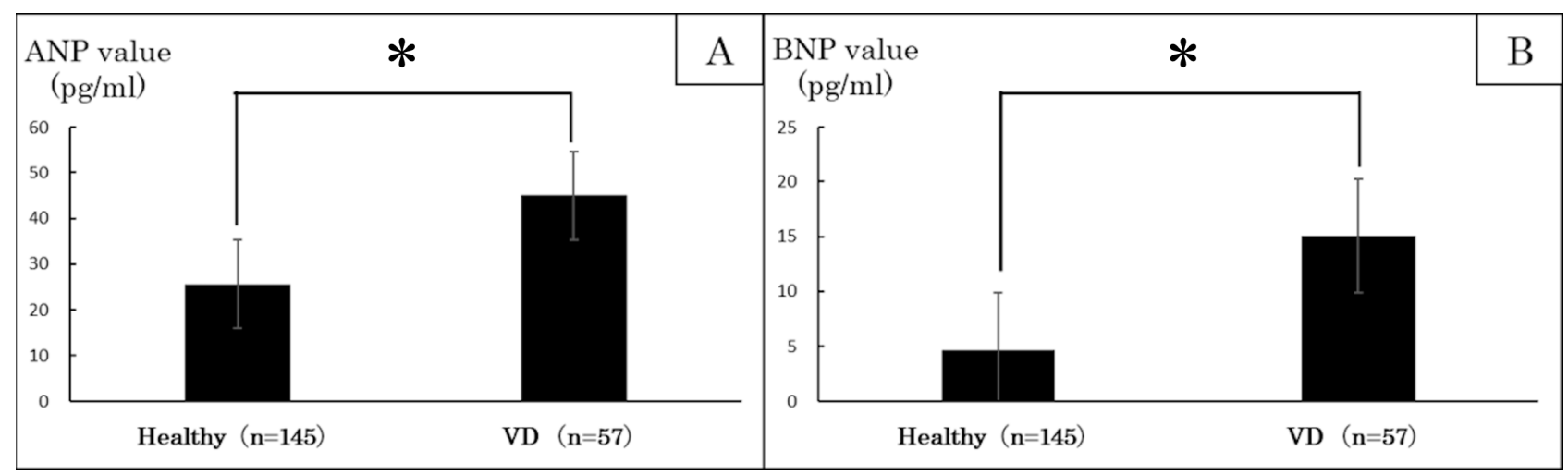

Fig. 3. Comparison of the atrial natriuretic peptide (ANP) (A) and brain natriuretic peptide (BNP) (B) levels in healthy and valvular disease (VD) monkeys. The ANP and BNP values differ significantly between the healthy and VD monkeys $(* P<0.05)$. 

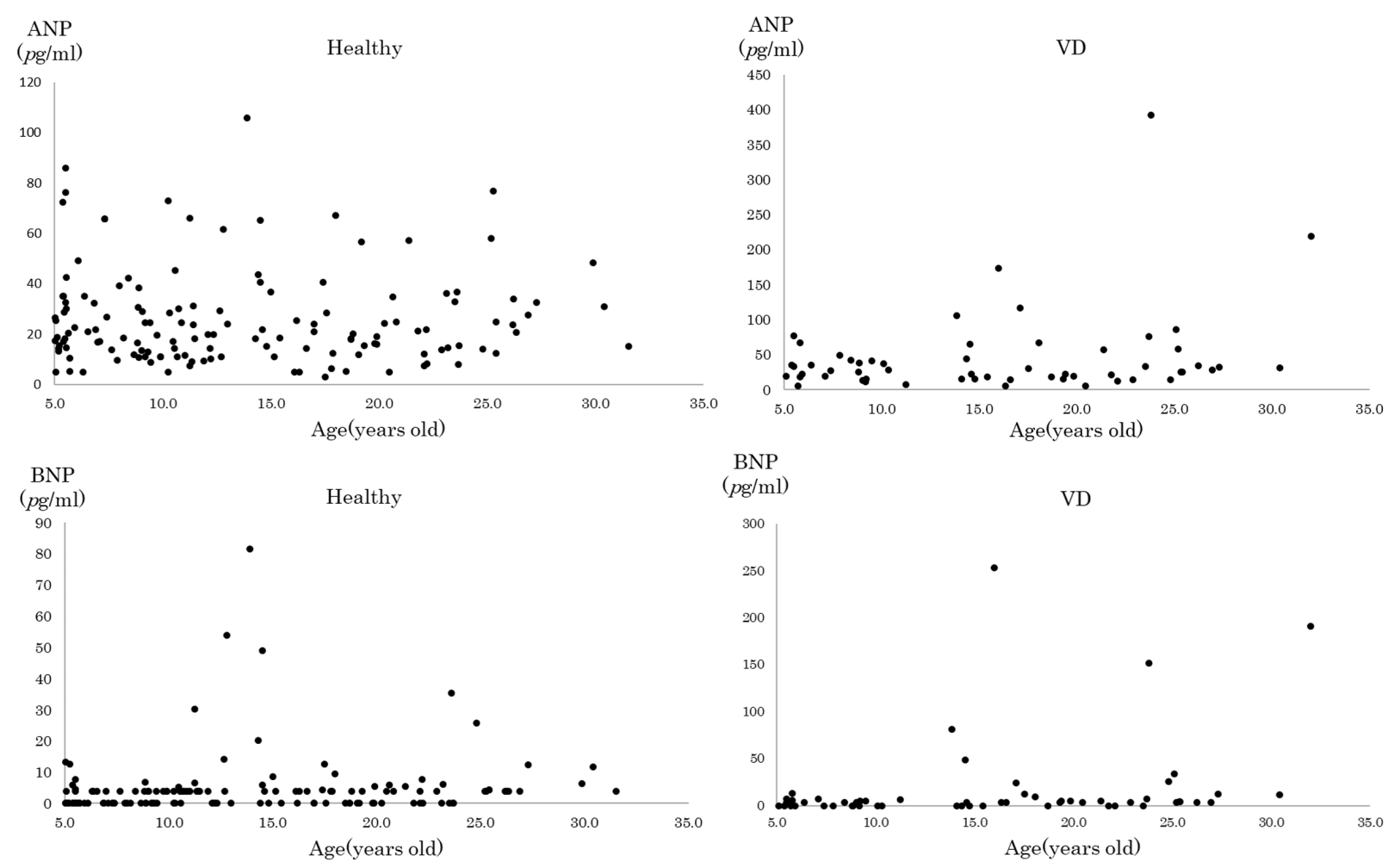

Fig. 4. The relationship between age and the levels of atrial natriuretic peptide (ANP) and brain natriuretic peptide (BNP). There was no correlation between age and the cardiac hormone levels $(P>0.05$, data not shown). The detection limit of BNP is $4.0 \mathrm{pg} / \mathrm{ml}$, and individuals with extremely low BNP levels are shown as having a BNP level of $0.01 \mathrm{pg} / \mathrm{ml}$.
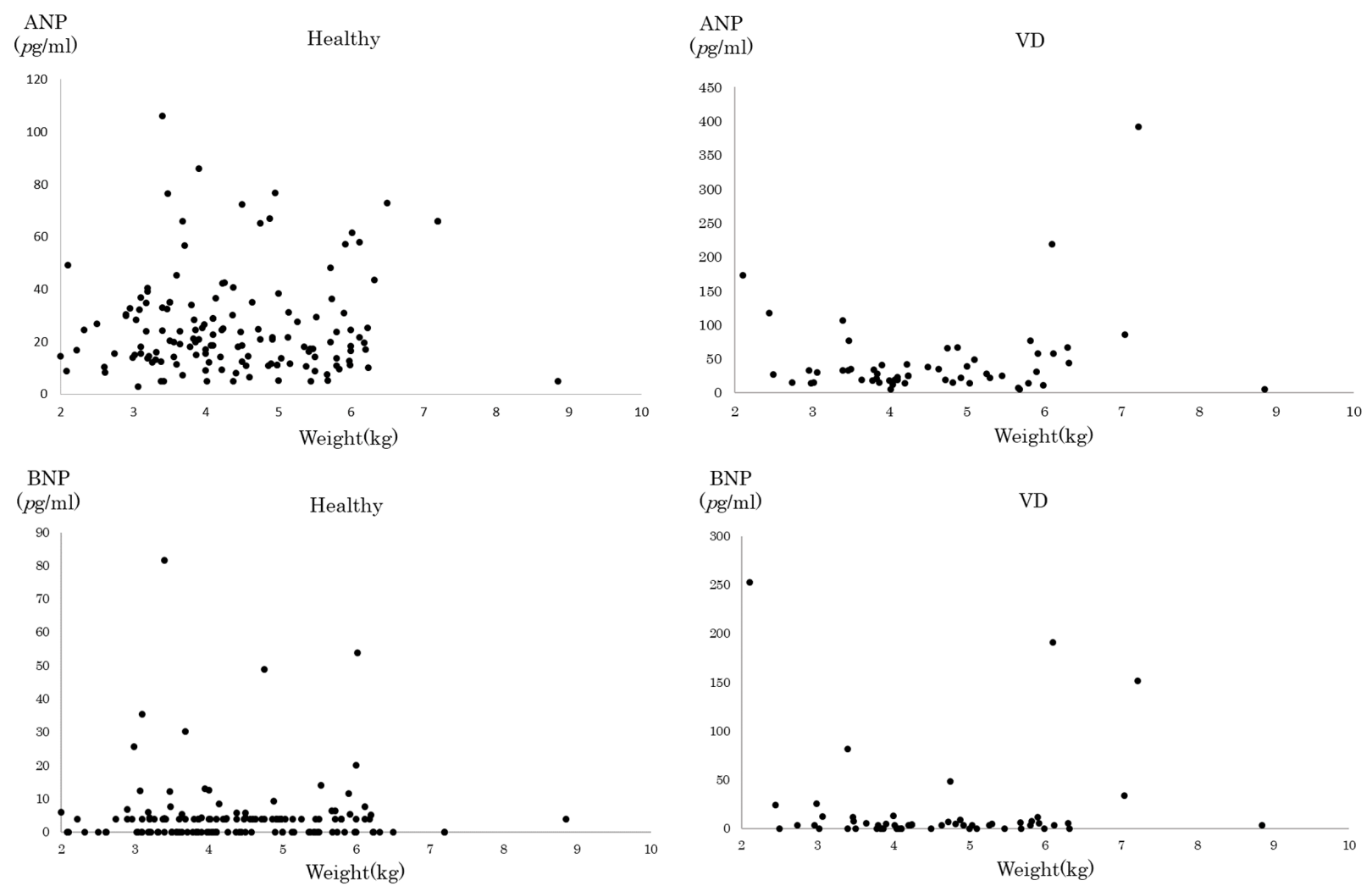

Fig. 5. The relationship between weight and the levels of atrial natriuretic peptide (ANP) and brain natriuretic peptide (BNP). There was no correlation between weight and the levels of ANP and BNP $(P>0.05$, data not shown). The detection limit of BNP is $4.0 \mathrm{pg} / \mathrm{ml}$, and individuals with extremely low BNP levels are shown as having a BNP level of $0.01 \mathrm{pg} / \mathrm{ml}$. 


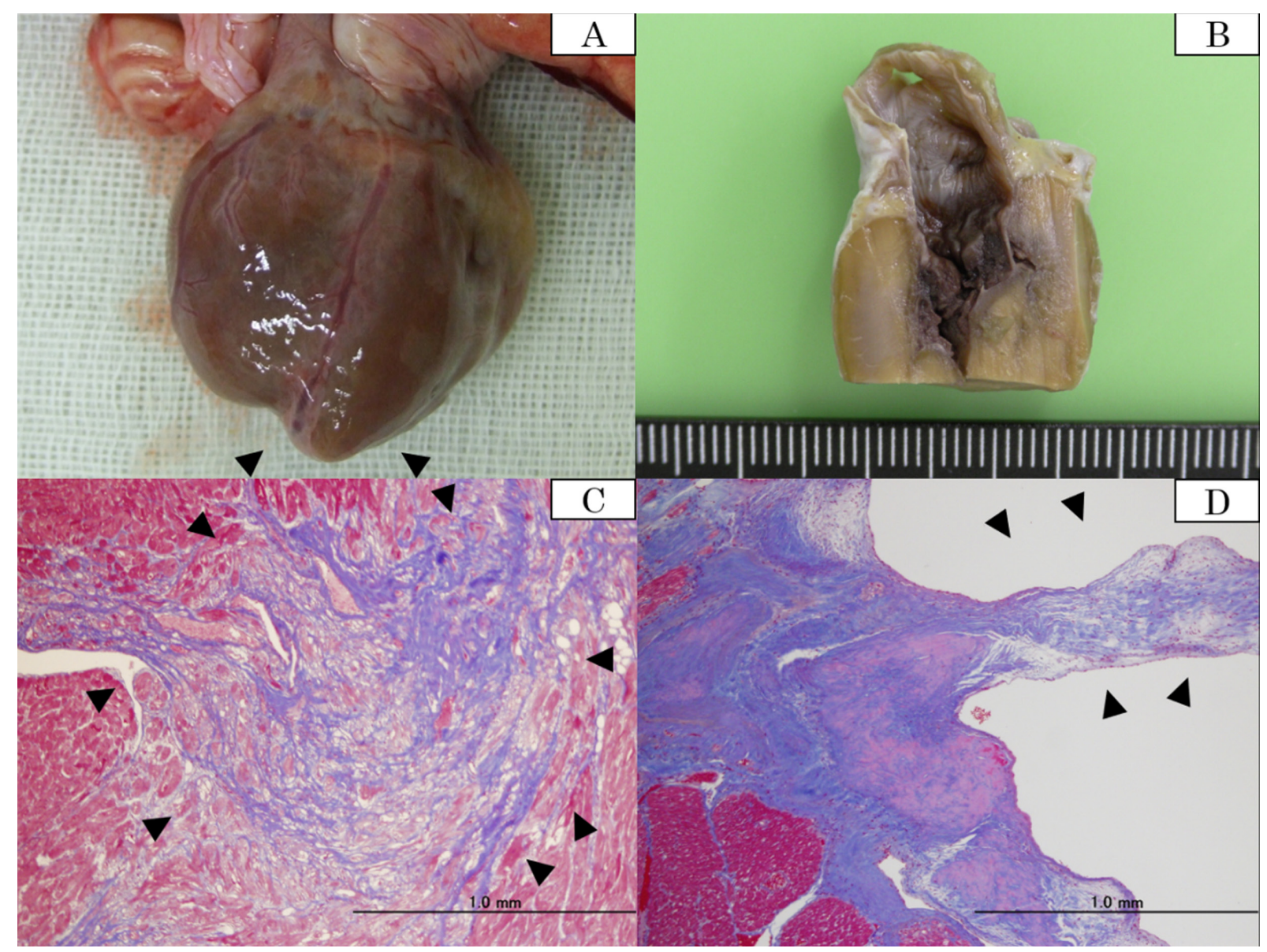

Fig. 6. Histopathological examination of valvular disease (VD) monkeys. A gross specimen showing an enlarged left ventricle (arrowheads) from a monkey with severe MR (A). A sagittal section showing fibrosis in the left ventricle (B). Masson's trichrome staining showing fibrosis in the left ventricular free wall (arrowheads) (C). Masson's trichrome staining showing mitral valve fibrosis (arrowheads) (D). The samples used for the histopathological examination were from the same individuals that were shown to have MR in the echocardiograms in Fig. 2.

compensate to preserve the hemodynamics of the body. This process may lead to high blood pressure and increases in the levels of cardiac hormones. ANP is secreted by atrial myocytes, and the levels increase with myocardial extension. The ANP level is a significant parameter in human medicine that is used to diagnose heart failure and to estimate the prognosis of heart disease, such as congestive heart failure $[19,21]$. The ANP level is useful not only in humans, but also in veterinary medicine. In canines, the ANP level is useful for the diagnosis of congestive heart failure, such as MR [4].

Since VD is a chronic heart disease, most of the monkeys involved in this study are still alive as of the time of this writing. Histopathology samples were taken from cases that suffered from serious symptoms, and these cases showed high levels of ANP and BNP due to serious enlargement. Because of that samples for histopathology are still not enough to make conclusions, the relationship between the histopathology and the levels of ANP and BNP remains unclear.

Although VD in nonhuman primates has been receiving a lot of attention in the human medical field [2, 9, 24], there has been no report on the usefulness of cardiac hormones for the diagnosis of VD in monkeys.

Similar to in humans, our data suggest that the levels of ANP and BNP may both be important leading indicators of cardiac disease in nonhuman primates. In humans, the level of NT-proBNP, a hormone that is produced by the decomposition of the BNP precursor proBNP, is also an important cardio-specific marker for heart failure $[6,17,28]$. However, NT-proBNP has specificities not only between animal species, but also between human races [16]. This is a reason why we choose to use BNP in this study.

The sequence of ANP does not differ between species [1], but the sequence of BNP does differ between animal species. In this study, the BNP levels in some samples were below the $4.0 \mathrm{pg} / \mathrm{ml}$ detection limit. It may be possible that the BNP sequence of monkeys is slightly different from that of humans. In a previous study that investigated the entire coding region of BNP in Japanese and cynomolgus monkeys, pro-BNP was found to comprise 106 amino acid residues while the mature BNP comprised 32 amino acid residues, and the coding region was found to differ slightly from that of humans. In the prepro-BNP, a T nucleotide in Japanese monkeys was a $\mathrm{C}$ in cynomolgus monkeys, but the deduced amino acid sequences were the same. The mature BNP of monkeys shows a high level of identity with that of humans: there is $91 \%$ identity in the prepro-BNP, and $97 \%$ identity in the mature region [1]. Based on this study, we made the supposition that the BNP sequence of monkeys is similar to that of humans. 
In humans, the BNP level is useful for the diagnosis of heart failure, but in a previous study, there were some cases in which the BNP levels were extremely low [30]. Individuals with low BNP levels may still be at risk of cardiac disease, such as ischemic heart disease [30]. In future studies, we should examine the population with a low BNP level as it may provide new insights and a new approach that differs from the measurement of cardiac troponin.

It has been reported that differences in cardiac hormone levels are observed between human women and men, and that the ANP levels are higher in females than in males $[5,18,26]$. This sex difference may be due to estrogen regulation in humans [18, 26]. However, such differences between the sexes were not seen in the monkeys in this study. This discrepancy may be due to the fact that all of the monkeys in this study were bred in cages, and their exercise load and diet differed from those of humans. It has also been reported that human females have a higher risk of long-QT syndrome due to the increased levels of progesterone during pregnancy [7]. It is thought that progesterone is one of the factors for heart disease in women. As the next step for our research, we may focus on ANP and BNP levels in monkeys during pregnancy.

Human ANP and BNP levels increase with age $[5,18]$. However, this tendency was not seen in the present study, although the ANP and BNP levels in VD monkeys tended to increase a little (Fig. 3). In humans, the increase in ANP and BNP levels due to heart muscle fibrosis tends to occur from middle age to old age [8]. It is likely that the same tendency occurs in monkeys, but it is difficult to clarify as experimental monkeys are bred in cages and have a different exercise load as humans.

Regarding the body weight, human ANP and BNP levels are decreased in obese individuals [13, 20, 32]. Levels of NTpro-ANP and NT-proBNP, which are ANP and BNP precursors, respectively, are also decreased in obese men [13]. However, this tendency was not seen in the present study. In macaque monkeys, no correlation was seen between the body weight and cardiac hormone levels in both healthy and VD monkeys. This discrepancy may be due to the fact that the macaque monkeys were bred in cages and had a different exercise load as humans. Natriuretic peptide receptor-C (NPR-C) on adipocytes also affect the BNP levels in humans $[13,20]$; however, there has been no report on NPR-C in macaques.

In human VD, the levels of natriuretic peptides (ANP and BNP) increase with the progression of heart fibrosis [25]. ANP and BNP are cardiac hormone regulators of cardiovascular homeostasis. As heart fibrosis progresses, myocardial extension causes an increase in the secretion of ANP, and ventricular remodeling causes the levels of BNP to increase [31]; our present data support these findings (Fig. 3).

This study established reference ranges for the cardiac hormones ANP and BNP in healthy monkeys. The ANP and BNP levels are used as indicators of cardiac damage in not only humans, but also in canines and felines. In this study, increases in the ANP and BNP values were also observed in VD monkeys. These results showed that cardiac hormone levels are also increased by heart damage and myocardial extension in cynomolgus monkeys. From this, it is speculated that ANP and BNP levels also increase in heart diseases other than VD.

In conclusion, the ANP and BNP levels are important leading indicators of cardiac disease in nonhuman primates, and VD monkeys are a useful nonhuman primate model for the study of cardiac disease for human medicine.

POTENTIAL CONFLICTS OF INTEREST. The authors have nothing to disclose.

ACKNOWLEDGMENTS. We thank Yuko Katakai and Chieko Ohno from the Corporation for Production and Research of Laboratory Primates for the care and handling of the monkeys, as well as Rie Houzouji and Masahiro Furuya for their excellent technical assistance. This work was supported by grants from JSPS KAKENHI (grant numbers 19590834, 24615009, and 15K07789) and the Japan Agency for Medical Research and Development (grant number 20ak0101047h0005).

\section{REFERENCES}

1. Abdelalim, E. M., Takada, T., Torii, R. and Tooyama, I. 2006. Molecular cloning of BNP from heart and its immunohistochemical localization in the hypothalamus of monkey. Peptides 27: 1886-1893. [Medline] [CrossRef]

2. Ageyama, N., Kurosawa, H., Fujimoto, O., Uehara, T., Hiroe, M., Arano, Y., Yoshida, T., Yasutomi, Y. and Imanaka-Yoshida, K. 2019. Successful Inflammation Imaging of Non-Human Primate Hearts Using an Antibody Specific for Tenascin-C. Int. Heart J. 60: 151-158. [Medline] [CrossRef]

3. Aizawa, K., Ageyama, N., Yokoyama, C. and Hisatsune, T. 2009. Age-dependent alteration in hippocampal neurogenesis correlates with learning performance of macaque monkeys. Exp. Anim. 58: 403-407. [Medline] [CrossRef]

4. Asano, K., Masuda, K., Okumura, M., Kadosawa, T. and Fujinaga, T. 1999. Plasma atrial and brain natriuretic peptide levels in dogs with congestive heart failure. J. Vet. Med. Sci. 61: 523-529. [Medline] [CrossRef]

5. Clerico, A., Del Ry, S., Maffei, S., Prontera, C., Emdin, M. and Giannessi, D. 2002. The circulating levels of cardiac natriuretic hormones in healthy adults: effects of age and sex. Clin. Chem. Lab. Med. 40: 371-377. [Medline] [CrossRef]

6. Gaggin, H. K. and Januzzi, J. L. Jr. 2013. Biomarkers and diagnostics in heart failure. Biochim. Biophys. Acta 1832: 2442-2450. [Medline] [CrossRef]

7. Garg, L., Garg, J., Krishnamoorthy, P., Ahnert, A., Shah, N., Dusaj, R. S. and Bozorgnia, B. 2017. Influence of Pregnancy in Patients With Congenital Long QT Syndrome. Cardiol. Rev. 25: 197-201. [Medline] [CrossRef]

8. Gazoti, D.C.R., Mesiano M. L.B. and Rodrigues, de S. R. 2001. Age related changes of the collagen network of the human heart. Mech. Ageing HV. Dev. 122: 1049-1058.

9. Goto, Y., Hiramatsu, Y., Ageyama, N., Sato, S., Mathis, B. J., Kitazawa, S., Matsubara, M., Sakamoto, H. and Sato, Y. 2019. Rolipram plus Sivelestat inhibits bone marrow-derived leukocytic lung recruitment after cardiopulmonary bypass in a primate model. J. Artif. Organs 22: 44-52. [Medline] [CrossRef]

10. Grewal, J., McKelvie, R. S., Persson, H., Tait, P., Carlsson, J., Swedberg, K., Ostergren, J. and Lonn, E. 2008. Usefulness of N-terminal pro-brain 
natriuretic peptide to predict cardiovascular outcomes in patients with heart failure and preserved left ventricular ejection fraction. Am. J. Cardiol. 102: 733-737. [Medline] [CrossRef]

11. Honjo, S. 1985. The Japanese Tsukuba Primate Center for Medical Science (TPC): an outline. J. Med. Primatol. 14: 75-89. [Medline] [CrossRef]

12. Honjo, S. 1986. Guiding Principles for animal experiments using nonhuman primates. Primate Rep. 2: 111-113. [CrossRef]

13. Horwich, T. B., Hamilton, M. A. and Fonarow, G. C. 2006. B-type natriuretic peptide levels in obese patients with advanced heart failure. $J . A m$. Coll. Cardiol. 47: 85-90. [Medline] [CrossRef]

14. Institute of Laboratory Animal Research 2011. Guide for the Care and Use of Laboratory Animals. National Academies Press, Washington, D.C.

15. Izumi, C., Eishi, K., Ashihara, K., Arita, T., Otsuji, Y., Kunihara, T., Komiya, T., Shibata, T., Seo, Y., Daimon, M., Takanashi, S., Tanaka, H., Nakatani, S., Ninami, H., Nishi, H., Hayashida, K., Yaku, H., Yamaguchi, J., Yamamoto, K., Watanabe, H., Abe, Y., Amaki, M., Amano, M., Obase, K., Tabata, M., Miura, T., Miyake, M., Murata, M., Watanabe, N., Akasaka, T., Okita, Y., Kimura, T., Sawa, Y., Yoshida K., Japanese Circulation Society Joint Working Group. 2020. JCS/JSCS/JATS/JSVS 2020 Guidelines on the Management of Valvular Heart Disease. Circ. J. 84: $2037-2119$. [Medline] [CrossRef]

16. Koegelenberg, A. S., Smith, W., Schutte, R. and Schutte, A. E. 2016. IGF-1 and NT-proBNP in a black and white population: The SABPA study. Eur. J. Clin. Invest. 46: 795-803. [Medline] [CrossRef]

17. Li, X. F., Pan, D., Zhang, W. L., Zhou, J. and Liang, J. J. 2016. Association of NT-proBNP and interleukin-17 levels with heart failure in elderly patients. Genet. Mol. Res. 15: 1-7. [Medline]

18. Loke, I., Squire, I. B., Davies, J. E. and Ng, L. L. 2003. Reference ranges for natriuretic peptides for diagnostic use are dependent on age, gender and heart rate. Eur. J. Heart Fail. 5: 599-606. [Medline] [CrossRef]

19. Matsuo, A., Nagai-Okatani, C., Nishigori, M., Kangawa, K. and Minamino, N. 2019. Natriuretic peptides in human heart: Novel insight into their molecular forms, functions, and diagnostic use. Peptides 111: 3-17. [Medline] [CrossRef]

20. Mehra, M. R., Uber, P. A., Park, M. H., Scott, R. L., Ventura, H. O., Harris, B. C. and Frohlich, E. D. 2004. Obesity and suppressed B-type natriuretic peptide levels in heart failure. J. Am. Coll. Cardiol. 43: 1590-1595. [Medline] [CrossRef]

21. Mukoyama, M., Nakao, K., Saito, Y., Ogawa, Y., Hosoda, K., Suga, S., Shirakami, G., Jougasaki, M., Obata, K., Yasue, H., Kambayashi, Y., Inouye, K. and Imura, H. 1991. Brain natriuretic peptide (BNP) as a novel cardiac hormone in humans: Evidence for an exquisite dual natriuretic peptide system, ANP and BNP. J. Clin. Invest. 87: 1402-1412. [Medline] [CrossRef]

22. Nakayama, T. 2005. The genetic contribution of the natriuretic peptide system to cardiovascular diseases. Endocr. J. 52: 11-21. [Medline] [CrossRef]

23. Nakayama, S., Koie, H., Kanayama, K., Katakai, Y., Ito-Fujishiro, Y., Sankai, T., Yasutomi, Y. and Ageyama, N. 2018. Utility of arterial blood gas, $\mathrm{CBC}$, biochemistry and cardiac hormones as evaluation parameters of cardiovascular disease in nonhuman primates. J. Vet. Med. Sci. 80: 1165-1173. [Medline] [CrossRef]

24. Nakayama, S., Koie, H., Kato-Tateishi, M., Pai, C., Ito-Fujishiro, Y., Kanayama, K., Sankai, T., Yasutomi, Y. and Ageyama, N. 2020. Establishment of a new formula for QT interval correction using a large colony of cynomolgus monkeys. Exp. Anim. 69: 18-25. [Medline] [CrossRef]

25. Potter, L. R., Yoder, A. R., Flora, D. R., Antos, L. K. and Dickey, D. M. 2009. Natriuretic peptides: their structures, receptors, physiologic functions and therapeutic applications. Handb. Exp. Pharmacol. 191: 341-366. [Medline] [CrossRef]

26. Redfield, M. M., Rodeheffer, R. J., Jacobsen, S. J., Mahoney, D. W., Bailey, K. R. and Burnett, J. C. Jr. 2002. Plasma brain natriuretic peptide concentration: impact of age and gender. J. Am. Coll. Cardiol. 40: 976-982. [Medline] [CrossRef]

27. Sharma, V., Stewart, R. A., Lee, M., Gabriel, R., Van Pelt, N., Newby, D. E. and Kerr, A. J. 2016. Plasma brain natriuretic peptide concentrations in patients with valvular heart disease. Open Heart 3: e000184. [Medline] [CrossRef]

28. Sitar Taut, A. V., Pop, D. and Zdrenghea, D. T. 2015. NT-proBNP values in elderly heart failure patients with atrial fibrillation and diabetes. $J$. Diabetes Complications 29: 1119-1123. [Medline] [CrossRef]

29. Stone, G. W., Vahanian, A. S., Adams, D. H., Abraham, W. T., Borer, J. S., Bax, J. J., Schofer, J., Cutlip, D. E., Krucoff, M. W., Blackstone, E. H., Généreux, P., Mack, M. J., Siegel, R. J., Grayburn, P. A., Enriquez-Sarano, M., Lancellotti, P., Filippatos, G., Kappetein A. P., Mitral Valve Academic Research Consortium (MVARC). 2015. Clinical trial design principles and endpoint definitions for transcatheter mitral valve repair and replacement: part 1: clinical trial design principles: a consensus document from the mitral valve academic research consortium. J. Am. Coll. Cardiol. 66: 278-307. [Medline] [CrossRef]

30. Sugawa, S., Masuda, I., Kato, K. and Yoshimura, M. 2018. Increased levels of cardiac troponin i in subjects with extremely low b-type natriuretic peptide levels. Sci. Rep. 8: 5120-5128. [Medline] [CrossRef]

31. Tamura, N., Ogawa, Y., Chusho, H., Nakamura, K., Nakao, K., Suda, M., Kasahara, M., Hashimoto, R., Katsuura, G., Mukoyama, M., Itoh, H., Saito, Y., Tanaka, I., Otani, H. and Katsuki, M. 2000. Cardiac fibrosis in mice lacking brain natriuretic peptide. Proc. Natl. Acad. Sci. USA 97: 4239-4244. [Medline] [CrossRef]

32. Wang, T. J., Larson, M. G., Levy, D., Benjamin, E. J., Leip, E. P., Wilson, P. W. and Vasan, R. S. 2004. Impact of obesity on plasma natriuretic peptide levels. Circulation 109: 594-600. [Medline] [CrossRef]

33. Yoshida, T. and Fujimoto, K., editors. 2006. The TPRC handbook on the care and management of the laboratory cynomolgus. Springer Japan, Tokyo (in Japanese).

34. Yoshimura, M., Yasue, H. and Ogawa, H. 2001. Pathophysiological significance and clinical application of ANP and BNP in patients with heart failure. Can. J. Physiol. Pharmacol. 79: 730-735. [Medline] [CrossRef]

35. Zoghbi, W. A., Adams, D., Bonow, R. O., Enriquez-Sarano, M., Foster, E., Grayburn, P. A., Hahn, R. T., Han, Y., Hung, J., Lang, R. M., Little, S. H., Shah, D. J., Shernan, S., Thavendiranathan, P., Thomas, J. D. and Weissman, N. J. 2017. Recommendations for noninvasive evaluation of native valvular regurgitation: a report from the American Society of Echocardiography Developed in collaboration with the Society for Cardiovascular Magnetic Resonance. J. Am. Soc. Echocardiogr. 30: 303-371. [Medline] [CrossRef] 